Running head: TRUST THE LEADER, TRUST THE ORGANIZATION

\title{
Leader trustworthy behavior and organizational trust: The role of the immediate manager for cultivating trust
}

\begin{abstract}
Drawing from both trust-building theory and interpersonal trust literature, we investigate how trust between a leader and follower may be leveraged to influence organizational trust. We also explore the mediating mechanisms of this link and test a potential moderator. A cross-sectional, multi-foci design was adopted and participants were 201 employees within a public sector organization. Leader trustworthy behavior was found to predict organizational trust, mediated by trustworthiness perceptions and trust in the leader. Support for the boundary condition was found; namely, when leaders were more senior, the relationship between trustworthy behavior and organizational trust was stronger. The findings suggest that leaders can meaningfully influence organizational trust perceptions through the enactment of trustworthy behavior, although the strength of this effect varied as a function of their position.
\end{abstract}

Keywords: Trust-building, organizational trust, interpersonal trust, leader position 
TRUST THE LEADER, TRUST THE ORGANIZATION

Trust is a highly complex phenomenon which is characterized by both multilevel (individual, team, organization) and multiple causal role considerations (trust as a cause, outcome, mediator and moderator). Adding to the complexity is the presence of multireferent (interpersonal, team and organization) considerations (Fulmer \& Gelfand, 2012), making a myriad of different trust combinations possible within a given workplace. At each level of analysis the trust literature is flourishing, as illustrated by the burgeoning literature on interpersonal (leader-follower) trust (Searle et al., 2011), and the rapidly growing team trust literature (Fulmer \& Gelfand, 2012). Nevertheless, insights regarding organizational trust have so far lagged behind (Maguire \& Phillips, 2008). Such an omission is surprising given the significant benefits associated with employee trust in the organization.

Organizational trust is defined as "a psychological state comprising willingness to accept vulnerability based on positive expectations of an organization" (Fulmer \& Gelfand, 2012, p. 1174). While similarities exist in how both interpersonal and organizational trust at the individual level are defined, with core concepts of risk, vulnerability and positive expectations in common (Mayer, Davis \& Schoorman, 1995; Rousseau, Sitkin, Burt \& Camerer, 1998), the levels of risk and dependency are distinct across the two referents. Despite this, a tendency in the literature has been to consider trust manifest towards a given referent to be equivalent to that of another referent (Vanhala Puumalainen \& Blomqvist, 2011). This is often due to studies failing to specify the trust foci and instead using referents interchangeably (Mayer et al, 1995). Recent theorizing, however, has treated organizational trust as an important construct in its own right. As such, there have been frequent calls for research to more clearly examine trust across levels of organizational analysis (e.g., Rousseau et al., 1998), with an emphasis on the importance of looking at multiple referents simultaneously. Of the research which has measured more than one referent of trust in the same study, the relationship between interpersonal trust (typically trust in the leader) and trust 
TRUST THE LEADER, TRUST THE ORGANIZATION

in the organization has not been the focus, bar the reporting of significant correlations (for example, r =.32; Ayree, Budhwar \& Chen, 2002; .r = 41; Wong, Ngo \& Wong, 2003). Such findings underscore the distinctiveness of such trust foci which can manifest as different levels of trust, towards different referents, at the same time, and lead to different outcomes (Colquitt, Scott \& LePine, 2007). Research has begun to map out the divergent antecedents and outcomes associated with trust at the individual level in different referents (Dietz \& Den Hartog, 2006). While exploring the unique role of differing antecedents and outcomes is important, it is likely that a host of antecedents may be equally relevant in determining trust in multiple referents and such cross-fertilization of antecedents applied to multiple referents could hold important insights (Fulmer \& Gelfand, 2012). As such, research is sorely needed to examine the interplay of trust between different referents and in particular how trust translates from interpersonal to organizational (Zaheer, McEvily \& Perrone, 1998).

The main aim of this study is to investigate how trust in one referent, the leader, may be leveraged to influence trust in a different referent, the organization, at the individual level of analysis. Specifically, adopting a multi-foci approach, and drawing from trust-building theory, we examine the extent to which the leader, and their behavior, can meaningfully influence not only the trust employees have in them via trustworthiness perceptions, but also in the organization they represent. Further we test to see whether this trustworthy behavior, when enacted by a senior manager, is a stronger determinant of trust in the organization than that of middle managers.

We go beyond previous trust and leadership research in three principle ways. First, we investigate the potential for leaders, as key organizational agents, to leverage organizational trust through their own trust-inducing actions. While this is an idea alluded to theoretically (e.g., Gillespie \& Dietz, 2009), it has been largely neglected in the empirical literature. In doing so, we can determine the extent to which the antecedent of leader trustworthy behavior 
TRUST THE LEADER, TRUST THE ORGANIZATION

can drive trust in two distinct referents. This aim constitutes an important contribution to trust theory through providing support for the view that leaders can influence trust perceptions beyond the confines of the leader-follower relationship. Further, it responds to the need for research to more explicitly examine individual level trust in multiple referents, at the same time, and consider the interplay between the two (Fulmer \& Gelfand, 2012). Second, we examine if all leaders are equally instrumental in influencing trust in the organization or whether their capacity varies as a function of their position. Finally, drawing from both the interpersonal trust literature and trust-building theory we detail the mediating process through which leader trustworthy behavior influences organizational trust via trustworthiness perceptions and trust in the leader. In doing so, we provide a more detailed examination of the trust building process though empirically testing the role of various facets of leader behavior as antecedents of the different trustworthiness dimensions, and their contribution to trust for two key organizational referents.

\section{Theoretical background and hypotheses}

Studies of organizational trust typically focus on how features of the organization are important determinants of employee trust. For example, Searle et al. (2011) found that the HR policies and practices enacted by an organization send signals regarding the trustworthiness of the organization. In other research the organizations' justice system (Bernardin, Richey \& Castro, 2011) and characteristics of ongoing change (Kiefer, 2005), have been linked to lower levels of trust while perceptions of value congruence have been found to positively influence employee trust in the organization (Edwards \& Cable, 2009). Such macro considerations feature strongly in theoretical models of organizational trust, such as the framework of trust repair presented by Gillespie and Dietz (2009). The authors identify four internal determinants of organizational trust, such as the restructuring of policies and the changing of culture and, as detailed above, some of these components have been the subject 
TRUST THE LEADER, TRUST THE ORGANIZATION

of empirical study. Gillespie and Dietz (2009) also recognize however the critical role more micro level processes, such as leadership and management practices, may play in determining organizational trust, and this constitutes the fourth internal determinant. Although the actions of senior management are important, the authors note that managers at all levels may send signals about the trustworthiness of the organization through their own behavior as role models and their influence and discretion over system's components (such as rewards and incentives). Accordingly, one's immediate manager should provide particularly salient and diagnostic information (Gillespie \& Dietz, 2009). Such an idea, while theoretically compelling, has largely been overlooked within empirical organizational trust research. Given that employee trust in the organization has been linked to a host of outcomes such as job satisfaction and organizational citizenship behavior (Fulmer \& Gelfand, 2012), and against a back drop of falling levels of trust being documented across the world (Avolio \& Walumbwa, 2014), perusing all possible determinants, especially those which can be meaningfully influenced within organizations, appears warranted. As such the important question becomes, what behaviors elicit such trust? In order to answer this question we turn to the trust-building literature.

While links have been drawn between certain types of leader behavior and employee trust, such as procedural justice (DeCremer \& Tyler, 2007) and transformational leadership (Podsakoff, MacKenzie, Moorman \& Fetter, 1990), the insights gained have been rather disjointed (Gillespie \& Mann, 2004), detailing generalized leadership styles rather than specific trust-building behaviors. Further, such leadership styles have largely only be considered within the context of interpersonal trust (e.g., how that leader influences employee trust in them). Extending beyond this we are interested in how leader enacted behaviors also influence trust in the organization as a distinct referent. In order to identify specific trustbuilding behaviors, which may be diagnostic of trust in more than one referent, we utilized 
TRUST THE LEADER, TRUST THE ORGANIZATION

Whitener, Brodt, Korsgaard and Werner's (1998) typology of trustworthy behavior. Drawing on this theoretical model we proposed a four stage process suggesting that leader trustworthy behavior influences organizational trust perceptions via trustworthiness perceptions and interpersonal trust. Below we extrapolate on each of these stages in turn.

\section{Trustworthy behavior leading to trustworthiness perceptions}

Considerable support exists for the proposition that trustworthiness perceptions will follow from trustworthy behavior. Trustworthy behaviors are defined as 'volitional actions to engender trust' which are proposed to provide a necessary foundation for subordinate's trust in the leader (Whitener et al., 1998: 516). Such voluntary behaviors are considered an important source of information about the internal character, motives and ultimately trustworthiness of a dyadic other (Ferrin, Dirks \& Shah, 2006). Whitener et al, (1998) identify five core behavioral markers of trustworthy behavior (including behavioral integrity, behavioral consistency, sharing and delegating control, open communication, and demonstrating concern), which are proposed to directly influence employee trust in the manager. Yet, the process through which the effect occurs is often unclear and not fully explored. The integrative model of organizational trust introduced by Mayer et al, (1995) provides a comprehensive account of the trusting process highlighting in particular the role of trustworthiness perceptions (along the dimensions of ability, integrity and benevolence) as key antecedents of the decision to trust. While in theory this process of trust is well accepted, empirically, links between particular behaviors and trust are 'presumed' to flow through trustworthiness perceptions (Fulmer \& Gelfand, 2012), however the nature of this influence across the different dimensions is rarely teased out. By combining the theoretical arguments made by Mayer et al, (1995) with Whitener et al.'s (1998) trust-building framework, we seek to test and extend this persuasive model of trustworthy behavior and provide a more detailed account of the trust-building process through arguing that these trust building behaviors are 
TRUST THE LEADER, TRUST THE ORGANIZATION

likely to influence trust in the leader via trustworthiness perceptions. Importantly we expect, based on the theoretical rationale provided below, for these behaviors to elicit different trustworthiness perceptions.

Despite the tripartite conceptualization of trustworthiness described by Mayer et al, (1995), trustworthiness has largely been measured as a composite construct, combining all three elements. A handful of studies (Caldwell \& Hayes, 2007; Colquitt \& Rodell, 2011; Frazier, Johnson, Gavin, Gooty \& Snow, 2010) do however provide support for the unique interdependencies of these trustworthiness dimensions in determining valued outcomes. Scholars have attributed trust-building to cognitive and affective bases, driven by the behavior of the dyadic other. From a theoretical perspective, a more fine-grained analysis of this trust-building process is important and scholars such as Colquitt et al (2007) have been calling for studies to examine trustworthiness at the dimension level so that the nuances of these critical trusting beliefs can be more clearly understood. Through examining more closely the dimensions in isolation we consider what role a given aspect of trustworthiness plays in influencing the decision to trust and importantly identify the trustworthy behaviors which guide this. It is proposed that the behaviors described may vary in their instrumentality, and the consideration of trustworthiness dimensions should help tease out the relative importance and necessity of the three components. From a practical point of view, this would allow leaders to more effectively develop trust by engaging in behaviors that specifically target the dimension of trustworthiness that requires attention and are relevant to the particular organizational context. As shown in figure 1, the three dimensions of trustworthiness were used as an organizing framework through which to explore and contextualize Whitener et al's, (1998) behavioral markers further. In the following sections each of the behaviors is introduced and justification for their relevance to a given trustworthiness dimension is provided. 


\section{INSERT FIGURE 1 ABOUT HERE}

The first two dimensions of trustworthy behavior, termed behavioral consistency and behavioral integrity, are closely related to integrity trustworthiness as defined by Mayer et al. (1995). Behavioral consistency is described as predictability or reliability in behavior (Whitener et al. 1998). Mayer et al. (1995) argue that integrity is judged by examining the similarity between the leader's previous and current behaviors and the consistency between word and deed. Accordingly, if an individual is consistent in their behavior, this should contribute to perceptions of higher integrity trustworthiness. Whitener et al. (1998) in their definition of behavioral integrity discuss word-deed consistency, along with honesty, promise fulfilment and moral character, which closely aligns with the definition of integrity, as provided by Mayer et al (1995). Although behavioral consistency and behavioral integrity both reflect a consistency that serves to influence integrity trustworthiness perceptions, the two dimensions are considered distinct. The former refers to the reliability of leaders based upon past actions whereas the latter refers to consistency between what a leader says and what he or she does (Whitener et al., 1998). It is proposed that the demonstration of behavioral consistency and behavioral integrity will influence perceptions of integrity trustworthiness, which in turn should make an individual more willing to trust due to the sense of certainty such behaviors instill.

Benevolence trustworthiness perceptions are fostered when a trustor is perceived as having a positive orientation toward the trustee (Mayer et al., 1995), which can be manifested through care and concern for the well-being of the other, which maps perfectly onto Whitener et al.'s (1998) behavioral dimension of demonstrating concern. Whitener and colleagues propose that leaders, who show sensitivity and consideration for employee needs and act in a 
TRUST THE LEADER, TRUST THE ORGANIZATION

way that protects employee interests, will be considered more benevolent. Such behavior denotes a genuine interest in the employee's welfare, implying an attachment to the employee. In contrast, if a leader does not engage in such behaviors and instead takes advantage of their follower's vulnerability, they will be considered to lack benevolence trustworthiness (Podsakoff et al., 1990). Open communication is also hypothesized as a driver of benevolence trustworthiness, due to the emphasis upon consideration. Mayer et al. (1995) note that open and honest communication with a subordinate is often one behavioral indicator of benevolence as it reflects a positive orientation. Whitener's definition of communication is comprised of three factors: accurate information, explanations for decisions, and openness. A leader who can candidly explain tough decisions and communicate in a timely manner, should be perceived as more benevolent by followers (Frazier et al., 2010), and therefore trusted more.

The behavioral dimension of sharing and delegating control is hypothesized to build ability trustworthiness perceptions. The extent to which leaders involve employees in the decision making process has been shown to influence the development of trust (Podsakoff et al., 1990). Indeed, Gillespie and Mann (2004) found that consultative leadership (e.g., consulting others) predicted $67 \%$ of the variance in subordinates trust towards leadership. It is proposed here that, although not measured in prior studies, ability trustworthiness is a plausible mechanism that underlies the trust-building process. A leader who actively engages employees is likely to be considered more capable as they are able to delegate and share control in an effective manner, thus portraying ability trustworthiness.

\section{Trustworthiness perceptions leading to interpersonal trust}

The second stage of the mediation process relates to the link between trustworthiness perceptions and interpersonal trust. This link is a core tenant of the theoretical model 
TRUST THE LEADER, TRUST THE ORGANIZATION

described by Mayer et al, (1995) and has been the subject of significant research efforts (for example, Mayer \& Davis, 1999). Colquitt et al, (2007), in their meta-analysis, found strong evidence to support the importance of all three trustworthiness dimensions as each factor was empirically found to contribute a unique and separable perspective to consider the trustee. Therefore, the three dimensions of trustworthiness have been linked to interpersonal trust both theoretical and empirically. We expect to replicate this pathway.

\section{Interpersonal trust leading to organizational trust}

The final stage of the mediation process relates to the link between trust in the leader and organizational trust perceptions. Employees plausibly look to their immediate managers to, among other things, make sense of organizational life (Eisenberger et al, 2010). Moreover, individuals are highly motivated to accurately make trusting decisions due to the risk inherent in misplaced trust. This is especially true when the referent is the organization as the level of dependency and vulnerability is likely to be higher between employees and their organization than between employees and their immediate managers (Mayer et al., 1995). The former referent is more distal and the employee is likely to have less information to base trusting perceptions on, and will therefore look to other available sources. The salience of the immediate leader-follower relationship, where the behavior of the leader can be more readily observed, is likely to serve as a strong basis for such perceptions. In support of such propositions, a study by Sousa-Lima, Michel and Caetano (2013) found perceptions of supervisory support predicted trust in the organization. To summarize, it is predicted here that a meaningful amount of variance in organizational trust can be accounted for by the immediate manager's trustworthy behavior. We argue that this is due to the trustworthiness these behaviors engender, which in turn leads to more trust, firstly in the leader, and then in the organization. 
TRUST THE LEADER, TRUST THE ORGANIZATION

Hypothesis 1. Leader integrity trustworthy behavior will positively influence trust in the organization, via its effects on integrity trustworthiness and trust in the leader.

Hypothesis 2. Leader ability trustworthy behavior will positively influence trust in the organization, via its effects on ability trustworthiness and trust in the leader.

Hypothesis 3. Leader benevolence trustworthy behavior will positively influence trust in the organization, via its effects on benevolence trustworthiness and trust in the leader.

\section{The moderating role of organizational position}

A further aim of this research was to investigate whether features of the organizational structure served to either enhance or impede the previously discussed trust-building process. Gillespie and Dietz (2009) advance the idea that the working relationship between immediate managers and employees is of critical relevance to employee organizational trust. What the authors do not touch upon is the role played by the leader's seniority within the organization. To address this it is necessary to go beyond the design of the typical leadership study and examine these processes at different positions in the organization. It is likely that the more senior the leader, the more their behavior will be considered by the employees to be representative of the organization, due to their proximity to the top management team and the strategic decision making process. Although organizational trust in its truest sense reflects trust in an abstract system, Giddens (1990) also emphasizes the significance of people in the development of trust, in particular those who occupy roles representing the interface at which trust is built. Such a view is mirrored within the leadership literature wherein research places a premium on those at the top. For example, Upper-Echelons Theory (Hambrick, 2007) views the top management team as critical in shaping the fortune of the organization. Therefore, it is expected that the link between leader trustworthy behavior and organizational trust will be 
TRUST THE LEADER, TRUST THE ORGANIZATION

stronger, when the focal leader (whose trust-building behavior is being observed) is higher up the organization (i.e., moderation by the organizational position of the leader). Furthermore, we expect this moderating relationship to be equivalent across each of the trustworthiness dimensions.

Hypothesis $4 a$. Leader organizational position will moderate the integrity trustworthy behavior-organizational trust link in that the positive relationship will be stronger for senior managers than middle managers.

Hypothesis $4 b$. Leader organizational position will moderate the ability trustworthy behavior-organizational trust link in that the positive relationship will be stronger for senior managers than middle managers.

Hypothesis $4 c$. Leader organizational position will moderate the benevolence trustworthy behavior-organizational trust link in that the positive relationship will be stronger for senior managers than middle managers.

To briefly summarize, we are proposing that a leader is able to cultivate employee trust in the organization they represent through their demonstration of trustworthy behavior. We argue that such organizational trust can be leveraged due to the perceptions of trustworthiness and trust they inspire through their actions. Further, we propose that a leader's ability to do so will vary based on their position within the organization.

\section{Method}

\section{Sample and procedure}

The sample comprised of 201 full-time employees from a UK public sector organization. Of the respondents, 81 reported directly to a senior manager, and 120 reported directly to a middle manager. Participants were $62 \%$ female and averaged 48.1 years of age $(\mathrm{SD}=9.2)$, 
TRUST THE LEADER, TRUST THE ORGANIZATION

with 16.1 years of tenure in the organization $(\mathrm{SD}=10.4)$ and 3 years of tenure with their immediate manager $(\mathrm{SD}=3.4)$.

Participants were invited to complete an online survey. In order to test the propositions of this research it was necessary for the sample to include immediate managers who occupied positions at two distinct levels of the organizational hierarchy (i.e., either middle or senior management in this instance). It is important to note, however, that while the leaders differed in seniority, leader distance (i.e., the hierarchical distance between the employee and the leader) was kept constant (see Antonakis \& Atwater, 2002), allowing us to disentangle the confounding effects of leader distance from leader seniority. Employees reporting to a senior manager were identified and emailed by a member of the organization inviting them to participate in the study while an advert for the research was placed in an online newsletter and participants reporting to a middle manager were recruited this way. No incentive was offered for participation in the case of either participant sample.

\section{Measures}

Unless otherwise stated, respondents provided assessments of the following items on a five-point Likert-type response scale ranging from 1 (strongly disagree) to 5 (strongly agree). In all cases, participants were directed to answer the items which referred to their manager as the individual who they directly reported to.

Trustworthy behavior. Item generation and selection for the trustworthy behaviors was based on Whitener et al's, (1998) typology and the definitions provided. With the exception of behavioral consistency, established scales were used and selected based on their similarity to the behavioral facets described by Whitener et al (1998). When combined, the 13 items produced a reliable composite trustworthy behavior scale $(\alpha=.95)$. In the following 
TRUST THE LEADER, TRUST THE ORGANIZATION

section scales for each of the trustworthy behavioral facets, and their corresponding trustworthiness dimension, are described.

Behavioral integrity and consistency. Two items, taken from Simons, Friedman, Liu and McLean-Parks' (2007) behavioral integrity (BI) scale, were used to measure behavioral integrity with an example item being 'my manager keeps to the promises he/she makes to others'. Behavioral consistency refers to the reliability and predictability of leader behavior, and three items were generated which reflected this definition. An example item included 'my manager acts consistently across situations'. Together, the five items were highly reliable $(\alpha=.92)$ and were combined to represent a measure of integrity-trustworthy behavior.

Demonstrating concern and communication. Two scales, designed by Korsgaard, Brodt and Whitener (2002), were used to measure these benevolence-based trustworthy behaviors. The first scale consisted of three items, which assessed a leader's sensitivity and consideration of the needs and wellbeing of the employee, with an example item being 'my manager is interested in how I feel and how I am doing'. For the second scale three items were used to measure communication with an example item including 'my manager takes the time to explain his/her decisions thoroughly'. Due to the relevance of both communication and demonstrating concern behaviors for benevolence trustworthiness the six items were combined to produce a single highly reliable scale $(\alpha=.94)$.

Delegating control. Two items were used to measure the delegation of managerial control (Yukl, Wall \& Lepsinger, 1990). An example item included 'my manager feels confident delegating tasks to me'. Together these items demonstrated acceptable reliability ( $\alpha$ $=.74$ ) and thus were combined to create a measure of ability-trustworthy behavior. 
TRUST THE LEADER, TRUST THE ORGANIZATION

Leader trustworthiness. We adapted Schoorman, Mayer and Davis' (1996) trustworthiness scale to measure employee perceptions of leader trustworthiness. Three items were used to measure benevolence $(\alpha=.94)$, five items were used to measure integrity ( $\alpha=$ $.93)$, and two items were used to assess ability $(\alpha=.95)$. Together the 11 items produced a highly reliable ( $\alpha=.96)$ composite measure of leader trustworthiness.

Trust in the leader. We adopted an explicit approach to directly assess employee trust in the leader (see Colquitt et al., 2007) using Earley's (1986) two-item trust scale. The following items, 'how much trust do you place in your immediate manager?' and 'how willing are you to rely on your immediate manager?' were rated by on 5-point scale $(1=d o$ not trust/will not rely on, $5=$ do trust/will rely on $)$. Reliability for this scale was high $(\alpha=$ $.90)$.

Trust in the organization. We used a direct measure of employee trust in the organization taken from Searle et al, (2011). The following item, 'overall, to what extent do you trust your organization?' was rated on a seven-point scale (ranging from 1 a very low degree to 7 a very high degree). Single item measures have been used by trust researchers in the past (e.g., Ferrin et al, 2006; Jones \& Shah, 2015) and are appropriate when the item is constructed is a way which is clear and unambiguous, which is the case with direct measures.

Control variables. We controlled for participants gender and department. Initially we also measured and controlled for propensity to trust using a five-item scale $(\alpha=.74)$ designed by Huff and Kelley (2003) and employee grade. Due to the testing of our models at the dimension level we also controlled for the other dimension models. These additional controls were later removed from the analysis when shown to not significantly influence the findings so to retain power.

\section{Results}


TRUST THE LEADER, TRUST THE ORGANIZATION

\section{Measurement evaluation}

Before forming the scales for hypothesis testing, exploratory factor analysis (EFA) was conducted on the trustworthy behavior scale as it was a newly formed measure for the purpose of the study. Principle component analysis along with direct oblimin as the form of oblique rotation was used and strong support for the hypothesized three-factor solution was found along the dimensions of ability, integrity and benevolence, with $78 \%$ of the variance explained with all extraction items loading above .50 on the respective underlying dimension. We then assessed the construct validity of our measures using confirmatory factor analysis comparing the measurement model with three competing models. As trust in the organization was measured using a single item we modelled it by setting the error variance to equal the variance of the variable multiplied by .2 (Kline, 2011). As shown in Table 1, an eight-factor measurement model produced a significantly better level of model fit $\left(X^{2}=771.159, d f=297\right.$, $p=.00 ; \mathrm{CFI}=.91 ; \mathrm{NNFI}=.90 ; \mathrm{RMSEA}=.09 ; \mathrm{SRMR}=.05)$ when compared to the alternative models, based on the results of each chi-square difference test. Given the high correlations between some of our key predictor variables further analysis was conducted to test for any issues relating to multicollinearity. Specifically, we conducted a series of variance inflation factor (VIF) tests which showed that multicollinearity between the variables was not a problem as the highest value reported was 4.626.

INSERT TABLE 1 ABOUT HERE

\section{Hypothesis testing}

The means, standard deviations and correlation coefficients are presented in table 2 . 


\section{INSERT TABLE 2 ABOUT HERE}

To test our mediation hypotheses, we employed model 6 of a macro devised by Hayes (2012) in SPSS which allows the testing of the indirect effect between the predictor and the criterion variable through both mediators, in serial order, using bootstrapping (set to 1000 iterations). Three different models were specified to reflect the dimensions of integrity; ability and benevolence (see Figure 1).

Figures 2 and 3 identify the estimates from the structural path coefficients and Tables 3 and 4 provide estimates of the indirect effects along with the $95 \%$ bias corrected bootstrapped confidence intervals for our path estimates for the integrity and benevolence based models respectively. Reflecting firstly on the path coefficients, with the exception of Path $b^{1}$, which reflects the link between perceptions of trustworthiness (mediator 1) and the dependent variable, trust in the organization, all path coefficients were found to be significant for both the integrity model and the benevolence model. In contrast, only path b2, representing the link between trust in the leader and organizational trust was found to be significant for the ability model, all other path coefficients were found to be non-significant when controlling for benevolence and integrity, therefore the mediation was not examined further and hypothesis 2 was not supported.

INSERT FIGURE 2 ABOUT HERE 
TRUST THE LEADER, TRUST THE ORGANIZATION

As shown in Table 3 and figure 2, for the integrity model, integrity trustworthiness did not mediate the relationship between integrity trustworthy behavior and organizational trust $(\beta=-.20 ; 95 \% \mathrm{CI}[-.45, .02])$ however trust in the leader did mediate the relationship between integrity trustworthy behavior and organizational trust $(\beta=.16 ; 95 \% \mathrm{CI}[.07, .33])$. As predicted in Hypothesis 1, integrity trustworthiness perceptions and trust in the leader sequentially did mediate the relationship between integrity trustworthy behavior and organizational trust $(\beta=.23 ; 95 \% \mathrm{CI}[.11, .40])$. In the case of the benevolence model a similar pattern of results was obtained. The final specific indirect effect for the relationship between benevolence trustworthy behavior and organizational trust, via benevolence trustworthiness and trust in the leader was found to be significant trust $(\beta=.19 ; 95 \% \mathrm{CI}[.10$, .33]), thus providing support for Hypothesis 3 (see Table 4, Figure 3). The analyses reported above provides support for the view that the influence of leader trustworthy behavior extends beyond the leader-follower relationship due to the trustworthiness perceptions and trust it inspires in the case of behaviors denoting both integrity and benevolence based trust.

INSERT TABLE 3 ABOUT HERE

INSERT TABLE 4 ABOUT HERE 
TRUST THE LEADER, TRUST THE ORGANIZATION

In order to test Hypotheses 4a-4c we employed model 1 in Hayes' macro, which allows the testing of moderation effects. It was proposed that the positive relationship between leader trustworthy behavior and organizational trust would be stronger when senior managers were the target referent, compared to middle managers. As with the mediation analysis, these propositions were tested at the dimension level. Prior to analysis all the variables involved in the interaction terms were mean-centered (Aiken \& West, 1991). Within this analysis, organizational position was treated as a binary variable with values of 0 and 1 representing senior managers and middle managers, respectively. For the outcome variable of trust in the organization, the interaction of integrity trustworthy behavior and organizational position was found to be significant $(\beta=-.38),(\mathrm{t}(186)=-1.89, p<.05)$. Simple slope analysis revealed that the relationship between integrity trustworthy behavior and trust in the organization was significant at both levels of the moderator. However, as illustrated in figure 4 , the effect was stronger for senior managers $(\beta=.72, \mathrm{t}(186)=4.00, p<$ $.01)$ than middle managers $(\beta=.33, \mathrm{t}(186)=3.64, p<.01)$, thus supporting Hypothesis $3 \mathrm{a}$. As predicted, senior managers' integrity-building behaviors had a stronger leveraging effect on organizational trust than that of middle managers. Employees with leaders at various levels of the organization appear to be influenced by the observation of leader behavioral consistency and integrity when considering their willingness to be vulnerable to the actions of the organization. However, senior manager's level of integrity appears to be particularly diagnostic for cultivating trust in both the senior manager and in the organization more generally.

\section{INSERT FIGURE 4 ABOUT HERE}

For ability trustworthy behaviors, a different pattern of results was obtained. The interaction of ability trustworthy behavior and organizational position on trust in the 
TRUST THE LEADER, TRUST THE ORGANIZATION

organization was found to be significant, $(\beta=-.54, \mathrm{t}(186)=-2.60, p<.01)$. Interestingly, the conditional effects revealed that the relationship between ability trustworthy behavior and trust in the organization was significant for senior managers $(\beta=.64, \mathrm{t}(186)=3.51, p<.01)$ but not for middle managers $(\beta=.10, p=n . s)$. The results of this analysis, which lend support to Hypothesis $3 \mathrm{~b}$, are presented in figure 5.The findings would suggest that delegating control behaviors are relevant for organizational trust perceptions solely when an employee reports to a senior manager.

\section{INSERT FIGURE 5 ABOUT HERE}

For the benevolence model, the interaction of benevolence trustworthy behavior and organizational position on organizational trust was not found to be significant $(\beta=-.24, p=$ $n . s)$, therefore not supporting the predictions made within Hypothesis $3 \mathrm{c}$. The implications of this finding are reflected on in the discussion.

\section{Discussion}

Although there is a growing body of research on interpersonal trust (especially leaderfollower trust) within organizations, insights regarding how trust in the organization can be leveraged at the individual level are less well known (Maguire \& Phillips, 2008). In the present research, we sought to address this lacuna by integrating theoretical insights from a framework of leader-follower trust-building (Whitener et al., 1998) and a model of organizational trust repair (Gillespie \& Dietz, 2009), to examine a link between trust in these two referents through the consideration of leader trustworthy behavior. Compelling support was found for the hypothesized trust-building process, as the link between leader trustworthy behavior and employee trust in the organization was mediated in turn by leader 
TRUST THE LEADER, TRUST THE ORGANIZATION

trustworthiness and trust in the leader. Moreover, utilizing the view of trustworthiness as driven by ability, integrity and benevolence considerations, this mediational process was examined at the dimension level and was significant for both the integrity and benevolencebased models. Support was also found for the proposed boundary condition, as the link between leader trustworthy behaviors and organizational trust was stronger when such behaviors were enacted by senior as opposed to middle managers. Interestingly, however, this moderating effect of organizational position was confined to behaviors diagnostic of leader integrity and ability, but not benevolence. These findings have important implications for the understanding and leveraging of organizational trust, to which we now turn.

\section{Theoretical implications}

The present study makes a number of meaningful contributions to the literature. First, this paper contributes to the organizational trust literature by providing compelling evidence that leaders, with different organizational positions, do play a pivotal role in building trust not only towards themselves but the organization they represent. To date, empirical research on organizational trust has tended to focus almost exclusively on macro-level factors as antecedents of organizational trust. The results of this study highlight the need to consider the leader's behavior as an important determinant of trust in these two important referents. These findings are not only consistent with Gillespie and Dietz's (2009) theorizing on the determinants of organizational trust, but also a more general line of research in the organizational behavior literature which has shown that employees generalize their attitudes toward supervisors to the organization as a whole (e.g., Eisenberger et al., 2010). Our research, however, also breaks new ground by articulating the specific kinds of behaviors that help build organizational trust (and we revisit this important point below). 
TRUST THE LEADER, TRUST THE ORGANIZATION

Second, this study both tests and extends a dominant theoretical model of trustworthy behavior (Whitener et al, 1998), thus contributing to trust-building theory. The mapping of Mayer et al.'s (1995) trustworthiness dimensions to Whitener et al.'s (1998) framework serves to synthesize these two models of trust and allows for a greater level of specificity about how leader-follower trust-building efforts influence organizational trust. Specifically, these combined models now capture behaviors responsible for driving trust in two referents through differential pathways along the dimensions of integrity and benevolence. The configuration of trustworthy behavior to trustworthiness dimensions adopted within this research is largely supported by the theoretical propositions made by Burke, Sims, Lazzara and Salas (2007). It is worth noting that this study also developed, and tested, a scale of trustworthy behavior. A paucity of research exits that actually test models of trustworthy behavior, and this may be attributable, in part, to the lack of validated scales designed to measure trustworthy behavior. In developing a scale for the purposes of this study it is hoped that this will help to stimulate research on the important process of trust-building.

Finally, the fact that in the present study the effectiveness of the trust-building process varied as a function leader seniority in terms of organizational position and across different dimensions of trustworthiness constitutes an important contribution to both the leadership and trust literature. In a recent review of six dominant leadership approaches and their level of analysis, DeChurch, Hiller, Murase, Doty and Salas, (2010) found that the studies were mostly conducted within a particular organizational level, namely the lower echelons of management. In contrast, the design of our study conferred a critical advantage in that it examined leadership for two distinct positions in the organization, which have been relatively neglected by researchers - senior and middle management. Next, we discuss the key findings for each dimension of trustworthy behavior in turn. 
TRUST THE LEADER, TRUST THE ORGANIZATION

In general, the results that emerged as a function of leader's organizational position were in line with predictions. As expected, the influence of both integrity and ability trustworthy behavior on trust in the organization was stronger when these behaviors were enacted by senior managers rather than middle managers. Consistent with Upper-Echelons Theory (Hambrick, 2007), employees are likely to view senior managers as critical in shaping the direction and fortune of the organization. Therefore, when senior managers portray integrity (i.e., word-deed alignment and promise fulfilment) and ability (i.e., ability to share and delegate control) in their dealings with employees then this, in turn, engenders more confidence and trust in the organization in general. In contrast, and as predicted, middle manager's trust-building efforts generally had a weaker impact on organizational trust. For example, middle manager's level of ability did not significantly impact organizational trust. It seems that displays of competence by middle managers, though important for determining leader-follower trust perceptions, do not appear to influence trust in the organization as a whole. Presumably, this is due to such leaders possessing lower levels of discretion and impact in the organizational decision-making process. Interestingly, a contrasting pattern of results was found for benevolence trustworthy behavior in that it directly influenced organizational trust perceptions, irrespective of organizational position. This finding, though not originally hypothesized, reinforces the view that a primary determinant of employee trust in both the immediate manager and the organization revolves around a positive orientation based upon concern, wellbeing and communication (Albert \& Travaglione, 2003). It seems that displays of benevolence are critical for cultivating trust, and that such displays are equally important regardless of the position of the leader.

Taken together, our results reinforce the value of examining trustworthy behavior at the dimension level in order to tease out unique differences across the dimensions of ability, integrity and benevolence. If this research had solely adopted a composite measure of 
TRUST THE LEADER, TRUST THE ORGANIZATION

trustworthy behavior and trustworthiness (as is commonplace in the literature) the richness of these different trusting relationships would have been lost. Moreover, our results show that senior managers, in particular, are pivotal to building trust in organizations. This finding constitutes an important contribution of this study as there is a limited body of research which focuses on the nature and influence of trust in senior management (Albecht \& Travaglione, 2003), rather leadership perceptions are often assumed to be equivalent across levels of authority (DeChurch et al, 2010). Often when senior leaders are the foci of study this is achieved via indirect leadership research of a more distal nature. One implication of this approach is that the dynamics of influence will likely differ depending on how "close"' or "distant" the leader is to the trustee (Antonakis \& Atwater, 2002). Distance can be physical, social or reflect interaction frequency (Antonakis \& Atwater, 2002). If the distance between the employee and the leader varies across a sample, then some employees are rating a leader who is further removed from them, and their perceptions and impressions of that leader will differ compared to someone rating their immediate manager. The design of the present study, however, permitted us to disentangle the effects of leader distance from seniority, as the employees were rating the individual they reported directly to (thus the leader was 'close').

This permitted a more rigorous examination of the moderating effect of organizational position on the trust-building process described.

\section{Practical implications}

We envision two important practical implications based on our findings. The first relates to training and development initiatives designed to cultivate trusting relations with employees, which should be targeted at managers of all organizational positions. The present findings help identify some key facilitators of trustworthiness and as such, any model for workplace relations looking to promote or develop trust should look to encourage the five categories of behavior outlined by Whitener et al. (1998) and tested here. In this training, 
TRUST THE LEADER, TRUST THE ORGANIZATION

managers should be encouraged to monitor their trusting relations and identify where trustworthiness perceptions could be strengthened further and target such behaviors in an instrumental fashion so to facilitate trust in both themselves and the organization. Further, given the importance of benevolence-based considerations, leaders need to foster benevolent feelings within their employees, and as such, leadership development interventions may also look to include relational skills training as a way in which to promote effective communication and the demonstration of concern.

Our second practical implication is targeted more directly at senior managers. It is important for organizations to recognize that trust is an on-going process and that one-off interventions, such as the training described above, will have little positive impact unless they are enacted in conjunction with more permanent initiatives. Specifically, organizations need to ensure that policies and practices are built around the premise of on-going trustworthiness demonstration. Given the prominence of senior managers, and the significance of their behavior for determining trust in the organization, it is likely that their conduct will set a tone for the organization. Specifically, it is likely that senior manager's trustworthy behavior would be a significant determinant of organizational trust climates. Adopting the recommendations suggested here, garnered by the findings of this study, is one tangible and manageable way organizations can seek to facilitate organizational trust perceptions.

\section{Limitations}

There are a number of limitations associated with this research, mostly pertaining to methodological aspects of the design. The cross-sectional nature of this study is a concern as it precludes inferences of causality. Although strong theoretical arguments have been made for the direction of effects stemming from trust at the interpersonal level to the more distal organizational referent (see Whitener et al., 1998), the direction of causality cannot be 
TRUST THE LEADER, TRUST THE ORGANIZATION

unequivocally established. For example, it may be the case that the employees trust the organization and, as the organizations appoint the leaders, the trust afforded to the organization is also extended to those placed in positions of authority. Although such reasoning is feasible, the direction of causality assumed in this study seems more plausible given that one's immediate manager occupies a more proximal and salient reference point for gauging organizational trust (Gillespie \& Dietz, 2009). Nonetheless, prospective research designs should be conducted in the future so that the direction of effects can be more firmly established.

A second concern relates to the use of single source data. Such a follower-centric approach to data collection, although common (and necessary) when investigating employee perceptions of trust and leadership processes (e.g., Giessner, van Knippenberg, \& Sleebos, 2009), may raise concerns relating to common method bias (Podsakoff, MacKenzie \& Podsakoff, 2003). It is important to note, however, that such concerns do not apply to the interaction effects found in this study as common method variance in fact undermines interaction effects, making them more difficult to detect (Busemeyer \& Jones, 1983). Finally, although common method variance is a pervasive concern within self-report surveys, studies have demonstrated that its impact has been overstated (Spector, 2006). Nevertheless, future research, which includes multi-source data, should be collected in an effort to mitigate such concerns. As a related point, while not possible in the present study, future research should also look to consider whether interaction frequency between the leader and follower serves to facilitate the trust-building process described. Finally, when interpreting the pattern of results in this study it is important to consider the setting of this research, namely a public sector organization. Although UK organizations are currently experiencing unprecedented low levels of organizational trust, this has been particularly felt within the public sector as compared to the private and voluntary sectors (Hope-Hailey, Searle \& Dietz, 2012), and this 
TRUST THE LEADER, TRUST THE ORGANIZATION

may have implications for the generalizability of our findings to different organizational contexts. Nonetheless, the particular need for effective trust-building in the public sector also attests to both the timely and highly warranted nature of this research in this understudied context. Future studies should look to test the present model across different organizational sectors to explore these findings further.

To conclude, the results of this study offer several notable findings and contributions to the interpersonal trust, organizational trust and leadership literatures in terms of how leader trustworthy behavior may influence trust in two key organizational referents. Moreover, the insights obtained are informative at a practical level by clearly articulating ways to facilitate trust and support trust-building efforts within the workplace. Notwithstanding the importance of leader trust-building efforts, there are likely to be other contextual factors in organizations (e.g., HR practices) which cumulatively impact organizational trust (Gillespie \& Dietz, 2009). Nevertheless, given the salience and importance of leader behavior to employee perceptions of the organization (Eisenberger et al., 2010), proactive efforts to build and maintain trust, especially when enacted by senior managers, constitutes a valuable starting point for leveraging organizational trust. 
TRUST THE LEADER, TRUST THE ORGANIZATION

\section{References}

Aiken, L. S., \& West, S. G. (1991). Multiple Regression: Testing and interpreting interactions. London: Sage.

Albrecht, S., \& Travaglione, A. (2003). Trust in public-sector senior management. International Journal of Human Resource Management, 14, 76-92. doi: $10.1080 / 09585190210158529$

Antonakis, J., \& Atwater, L. (2002). Leader distance: A review and a proposed theory. Leadership Quarterly, 13(6), 673-704. doi: 10.1016/s1048-9843(02)00155-8

Aryee, S., Budhwar, P. S., \& Chen, Z. X. (2002). Trust as a mediator of the relationship between organizational justice and work outcomes: Test of a social exchange model. Journal of Organizational Behavior, 23, 267-285.doi:10.1002/job.138

Avolio, B.J., \& Walumbwa, F.O. (2014). Authentic leadership theory, research and practice: Steps taken and steps that remain. In D.V. Day (Ed.). The Oxford Handbook of Leadership and Organizations (pp. 331-356). New York: Oxford University Press. Bandura, A. (1977). Social learning theory. Englewood Cliffs, NJ: Prentice-Hall.

Bernardin, H., Richey, B. E., \& Castro, S. L. 2011. Mandatory and binding arbitration: Effects on employee attitudes and recruiting results. Human Resource Management, 50, 175-200. doi:10.1002/hrm.20417

Burke, C. S., Sims, D. E., Lazzara, E. H., \& Salas, E. (2007). Trust in leadership: A multilevel review and integration. The Leadership Quarterly, 18, 606-632. doi: 10.1016/j.leaqua.2008.11.005

Busemeyer, J. R., \& Jones, L. E. (1983). Analysis of multiplicative combination rules when the causal variables are measured with error. Psychological Bulletin, 93, 549-562. doi: 10.1037/0033-2909.93.3.549 
TRUST THE LEADER, TRUST THE ORGANIZATION

Caldwell, C., \& Hayes, L. A. (2007). Leadership, trustworthiness and the mediating lens. Journal of Management Development, 26, 261-281. doi:

$10.1108 / 02621710710732155$

Colquitt, J. A., \& Rodell, J. B. (2011). Justice, trust, and trustworthiness: A longitudinal analysis integrating three theoretical perspectives. Academy of Management Journal, 54(6), 1183-1206. doi:10.5465/amj.2007.0572

Colquitt, J. A., Scott, B. A., \& LePine, J. A. (2007). Trust, trustworthiness, and trust propensity: A meta-analytic test of their unique relationships with risk taking and job performance. Journal of Applied Psychology, 92, 902-927. doi: 10.1037/00219010.92 .4 .909

DeChurch, L. A., Hiller, N. J., Murase, T., Doty, D., \& Salas, E. (2010). Leadership across levels: Levels of leaders and their levels of impact. The Leadership Quarterly, 21, 1069-1085.doi: 10.1016/j.leaqua.2010.10.009

De Cremer, D., \& Tyler, T. R. (2007). The effects of trust in authority and procedural fairness on cooperation. Journal of Applied Psychology, 92, 639- 649.doi: 10.1037/00219010.92 .3 .639

Dietz, G., \& Den Hartog, D. N. (2006). Measuring trust inside organizations. Personnel Review, 35, 557-588. dx.doi.org/10.1108/00483480610682299

Earley, P. C. (1986). Trust, perceived importance of praise and criticism, and work performance: An examination of feedback in the United States and England. Journal of Management, 12, 457-473.doi: 10.1177/014920638601200402

Edwards, J. R., \& Cable, D. M. 2009. The value of value congruence. Journal of Applied Psychology, 94, 654-677. doi:10.1037/a0014891

Eisenberger, R., Karagonlar, G., Stinglhamber, F., Neves, P., Becker, T. E., GonzalezMorales, M. G., \& Steiger-Mueller, M. (2010). Leader-member exchange and 
TRUST THE LEADER, TRUST THE ORGANIZATION

affective organizational commitment: The contribution of supervisor's organizational embodiment. Journal of Applied Psychology, 95, 1085- 1103.

Ferrin, D. L., Dirks, K. T., \& Shah, P. P. (2006). Direct and indirect effects of third party relationships on interpersonal trust. Journal of Applied Psychology, 91, 870- 883. doi: 10.1037/0021-9010.91.4.870

Frazier, L. M., Johnson, P. D., Gavin, M., Gooty, J., \& Snow, B. D. (2010). Organizational justice, trustworthiness, and trust: A multifoci examination. Group and Organization Management, 35, 39-76. doi: 10.1177/1059601109354801

Fulmer, C. A., \& Gelfand, M. J. (2012). At What Level (and in Whom) We Trust Trust Across Multiple Organizational Levels. Journal of Management, 38(4), 1167-1230. doi.org/10.1177/0149206312439327

Giddens, A. (1990). The Consequences of Modernity, The Raymond Fred West Memorial Lectures. Stanford, CA: Stanford University.

Giessner, S. R., van Knippenberg, D., \& Sleebos, E. (2009). License to fail? How leader group prototypicality moderates the effects of leader performance on perceptions of leadership effectiveness. The Leadership Quarterly, 20, 434-451.

Gillespie, N., \& Dietz, G. (2009). Trust repair after organization-level failure. Academy of Management Review, 34, 127-145. doi: 10.5465/amr.2009.35713319

Gillespie, N., A., \& Mann, L. (2004). Transformational leadership and shared values: the building blocks of trust. Journal of Managerial Psychology, 19, 588-607. doi:10.1108/02683940410551507

Hambrick, D. C. (2007). Upper echelons theory: An update. Academy of Management Review, 32(2), 334-343. doi:10.5465/amr.2007.24345254

Hayes, A. F. (2012). PROCESS: A versatile computational tool for observed variable mediation, moderation, and conditional process modeling [White paper]. 
TRUST THE LEADER, TRUST THE ORGANIZATION

Hope-Hailey, V., Searle, R., \& Dietz, G. (2012). Where Has All the Trust Gone? London: Chartered Institute of Personnel and Development.

Huff, L. \& Kelley, L. (2003). Levels of organizational trust in individualist versus collectivist societies: A seven-nation study. Organization Science, 14, 81-90. doi: 10.1287/orsc.14.1.81.12807

Jones, S. L., \& Shah, P. P. (2015). Diagnosing the Locus of Trust: A Temporal Perspective for Trustor, Trustee, and Dyadic Influences on Perceived Trustworthiness. Journal of Applied Psychology. http://dx.doi.org/10.1037/ap10000041

Kiefer, T. 2005. Feeling bad: Antecedents and consequences of negative emotions in ongoing change. Journal of Organizational Behavior,26, 875-897. doi:10.1002/job.339

Kline, R. B. (2011). Principles and practice of structural equation modeling. Guilford press.

Korsgaard, M. A., Brodt, S. E., \& Whitener, E. M. (2002). Trust in the face of conflict: the role of managerial trustworthy behavior and organizational context. Journal of Applied Psychology, 87, 312 - 319. doi: 10.1037/0021-9010.87.2.312

Maguire, S., \& Phillips, N. (2008). 'Citibankers' at citigroup: A study of the loss of institutional trust after a merger. Journal of Management Studies, 45, 372-401. doi: 10.1111/j.1467-6486.2007.00760.x

Mayer, R. C., \& Davis, J. H. (1999). The effect of the performance appraisal system on trust in management. Journal of Applied Psychology, 84, 123- 136. doi.org/10.1037/00219010.84 .1 .123

Mayer, R. C., Davis, J. H., \& Schoorman, F. D. (1995). An integrative model of organizational trust. Academy of Management Review, 20, 709- 734. doi: 10.5465/amr.1995.9508080335

Podsakoff, P. M., MacKenzie, S. B., Lee, J., \& Podsakoff, N. P. (2003). Common method bias in behavioral research: A critical review of the literature and recommended 
TRUST THE LEADER, TRUST THE ORGANIZATION

remedies. Journal of Applied Psychology, 88, 879 -903. doi: 10.1037/00219010.88 .5 .879

Podsakoff, P. M., MacKenzie, S. B., Moorman, R. H., \& Fetter, R. (1990). Transformational leader behaviors and their effects on followers' trust in leader, satisfaction, and organizational citizenship behaviors. The Leadership Quarterly, 1, 107-142.

Rousseau, D. M., Sitkin, S. B., Burt, R. S., \& Camerer, C. (1998). Not so different after all: A cross-discipline view of trust. Academy of Management Review, 23, 393-404. doi: 10.5465/amr.1998.926617

Schoorman, F. D., Mayer, R. C., \& Davis, J. H. (1996). Organizational trust: philosophical perspectives and conceptual definitions. Academy of Management Review, 31, 337340. doi: 10.5465/amr.1996.27003218

Searle, R., Den Hartog, D. N., Weibel, A., Gillespie, N., Six, F., Hatzakis, T., \& Skinner, D. (2011). Trust in the employer: the role of high-involvement work practices and procedural justice in European organizations. The International Journal of Human Resource Management, 22, 1069-1092. doi: 10.1080/09585192.2011.556782

Simons, T., Friedman, R., Liu, L. A., \& McLean Parks, J. (2007). Racial differences in sensitivity to behavioral integrity: Attitudinal consequences, in-group effects, and" trickle down" among Black and non-Black employees. Journal of Applied Psychology, 92(3), 650-665. doi: 10.2139/ssrn.938208

Sousa-Lima, M., Michel, J. W., \& Caetano, A. (2013). Clarifying the importance of trust in organizations as a component of effective work relationships. Journal of Applied Social Psychology, 43(2), 418-427. doi: 10.1111/j.1559-1816.2013.01012.x

Spector, P. E. (2006). Method variance in organizational research truth or urban legend? Organizational Research Methods, 9, 221-232. 
TRUST THE LEADER, TRUST THE ORGANIZATION

Vanhala, M., Puumalainen, K., \& Blomqvist, K. (2011). Impersonal trust: The development of the construct and the scale. Personnel Review, 40, 485-513. doi:

$10.1108 / 00483481111133354$

Whitener, E. M., Brodt, S. E., Korsgaard, M. A., \& Werner, J. M. (1998). Managers as imitators of trust: An exchange relationship framework for understanding managerial trust building behavior. Academy of Management Review, 23, 513-529. doi:

$10.2307 / 259292$

Wong, Y. T., Ngo, H. Y., \& Wong, C. S. (2003). Antecedents and outcomes of employees' trust in Chinese joint ventures. Asia Pacific Journal of Management, 20(4), 481-499.

Yukl, G., Wall, S., \& Lepsinger, R. (1990). Preliminary report on validation of the managerial practices survey. In K.E. Clark \& M.B. Clark (Eds.), Measures of leadership. West Organge, NJ: Leadership Library America, pp. 223-238.

Zaheer, A., McEvily, B., \& Perrone, V. (1998). Does trust matter? Exploring the effects of interorganizational and interpersonal trust on performance. Organization Science, 9, 141-159.doi: 10.1287/orsc.9.2.141

\section{Table 1}

Fit Indices for Alternative Measurement Models

\begin{tabular}{lccccccc}
\hline \multicolumn{1}{r}{ Model } & $\boldsymbol{d} \boldsymbol{f}$ & $\boldsymbol{X}^{\mathbf{2}}$ & $\boldsymbol{X}^{2} / \boldsymbol{d} \boldsymbol{f}$ & CFI & NNFI & RMSEA & SRMR \\
\hline $\begin{array}{l}\text { Eight-factor } \\
\text { model }\end{array}$ & 297 & 771.159 & 2.60 & .91 & .90 & .09 & .05 \\
Four-factor & 319 & 1649.117 & 5.17 & .75 & .73 & .15 & .07
\end{tabular}


TRUST THE LEADER, TRUST THE ORGANIZATION

model

Two-factor model

324

.68

.16

.07

Single-factor

model

325

$2225.720 \quad 6.85$

.65

.62

.18

.12

Note:

Eight-factor model includes three facets of trustworthy behavior, three trustworthiness dimensions, trust in the leader, and organizational trust

Four-factor model collapses across trustworthiness dimensions and three facets of trustworthy behavior

Two-factor model collapses across leader trust variables (trustworthiness dimensions, trustworthy behavior and trust in the leader) and organizational trust 


\section{TRUST THE LEADER, TRUST THE ORGANIZATION}

\section{Table 2}

Means, Standard Deviations, Correlations of Variables and Chronbach's alphas

\begin{tabular}{|c|c|c|c|c|c|c|c|c|c|c|}
\hline Variables & Mean & S.d & 1 & 2 & 3 & 4 & 5 & 6 & 7 & 8 \\
\hline $\begin{array}{l}\text { 1. Integrity trustworthy } \\
\text { behavior }\end{array}$ & 3.60 & .950 & $(.92)$ & & & & & & & \\
\hline $\begin{array}{l}\text { 2. Ability trustworthy } \\
\text { behavior }\end{array}$ & 4.01 & .905 & $.60 * *$ & $(.74)$ & & & & & & \\
\hline $\begin{array}{l}\text { 3. Benevolence } \\
\text { trustworthy behavior }\end{array}$ & 3.52 & .961 & $.69 * *$ & $.59 * *$ & $(.94)$ & & & & & \\
\hline 4 Integrity trustworthiness & 3.58 & .870 & $.77 * *$ & $.51 * *$ & $.73 * *$ & (.93) & & & & \\
\hline 5. Ability trustworthiness & 3.74 & 1.05 & $.70 * *$ & $.43 * *$ & $.62 * *$ & $.76^{* *}$ & $(.95)$ & & & \\
\hline $\begin{array}{l}\text { 6. Benevolence } \\
\text { trustworthiness: }\end{array}$ & 3.14 & 1.00 & $.62 * *$ & $.50 * *$ & $.73 * *$ & $.77 * *$ & $.62 * *$ & $(.94)$ & & \\
\hline 7. Trust in the leader & 3.52 & 1.22 & $.69 * *$ & $.46^{* *}$ & $.65^{* *}$ & $.76^{* *}$ & $.74^{* *}$ & $.70 * *$ & $(.90)$ & \\
\hline 8. Trust in the organization & 2.86 & 1.22 & $.41 * *$ & $.24 * *$ & $.30 * *$ & $.34 * *$ & $.36^{* *}$ & $.38 *$ & $.47 * *$ & - \\
\hline
\end{tabular}

$* * p<.01 * p<.05$, Note: cronbach's alpha on the diagonal in parentheses. 
TRUST THE LEADER, TRUST THE ORGANIZATION

\section{Table 3}

Path Coefficients and Indirect Effects for Integrity Mediation Model

\begin{tabular}{|c|c|c|c|c|c|}
\hline & & & & \multicolumn{2}{|c|}{ Indirect Effects } \\
\hline & \multicolumn{3}{|c|}{$\begin{array}{c}\text { Path } \\
\text { Coefficients }\end{array}$} & \multirow[b]{2}{*}{ Estimate } & \multirow[b]{2}{*}{$\begin{array}{c}\text { Bias-Corrected } \\
\text { Bootstrap 95\% } \\
\text { Confidence } \\
\text { Interval }\end{array}$} \\
\hline & $\begin{array}{c}\text { to } \\
\text { Organizational } \\
\text { Trust }\end{array}$ & $\begin{array}{c}\text { to leader } \\
\text { trustworthiness }\end{array}$ & $\begin{array}{l}\text { to trust in } \\
\text { the leader }\end{array}$ & & \\
\hline Trustworthy behavior & $0.33(.13)$ & $0.70(.04)$ & $0.36(.09)$ & & \\
\hline Leader trustworthiness & $-0.29(.16)$ & & $0.76(.10)$ & & \\
\hline Trust in the leader & $0.44(.10)$ & & & & \\
\hline Total & & & & $.19(.10)$ & $-.03, .38$ \\
\hline $\mathrm{TwB} \rightarrow \mathrm{LTw} \rightarrow \mathrm{OT}$ & & & & $-.20(.12)$ & $-.45, .18$ \\
\hline $\mathrm{TwB} \rightarrow \mathrm{TL} \rightarrow \mathrm{OT}$ & & & & $.16(.07)$ & $.07, .33$ \\
\hline $\mathrm{TwB} \rightarrow \mathrm{LTw} \rightarrow \mathrm{TL} \rightarrow \mathrm{OT}$ & & & & $.24(.07)$ & $.11, .40$ \\
\hline
\end{tabular}


TRUST THE LEADER, TRUST THE ORGANIZATION

\section{Table 4}

Path Coefficients and Indirect Effects for Benevolence Mediation Model

\begin{tabular}{|c|c|c|c|c|c|}
\hline & & & & \multicolumn{2}{|c|}{ Indirect Effects } \\
\hline & \multicolumn{3}{|c|}{$\begin{array}{c}\text { Path } \\
\text { Coefficients }\end{array}$} & \multirow[b]{2}{*}{ Estimate } & \multirow[b]{2}{*}{$\begin{array}{c}\text { Bias-Corrected } \\
\text { Bootstrap 95\% } \\
\text { Confidence } \\
\text { Interval }\end{array}$} \\
\hline & $\begin{array}{c}\text { to } \\
\text { Organizational } \\
\text { Trust }\end{array}$ & $\begin{array}{c}\text { to leader } \\
\text { trustworthiness }\end{array}$ & $\begin{array}{c}\text { to trust in the } \\
\text { leader }\end{array}$ & & \\
\hline Trustworthy behavior & $0.07(.13)$ & $0.77(.05)$ & $0.37(.09)$ & & \\
\hline Leader trustworthiness & $0.13(.13)$ & & $0.58(.09)$ & & \\
\hline Trust in the leader & $0.42(.10)$ & & & & \\
\hline Total & & & & $.45(.17)$ & $.23, .83$ \\
\hline $\mathrm{TwB} \rightarrow \mathrm{LTw} \rightarrow \mathrm{OT}$ & & & & $.10(.13)$ & $-.11, .35$ \\
\hline $\mathrm{TwB} \rightarrow \mathrm{TL} \rightarrow \mathrm{OT}$ & & & & $.16(.08)$ & $.06, .35$ \\
\hline $\mathrm{TwB} \rightarrow \mathrm{LTw} \rightarrow \mathrm{TL} \rightarrow \mathrm{OT}$ & & & & $.19(.06)$ & $.10, .33$ \\
\hline
\end{tabular}




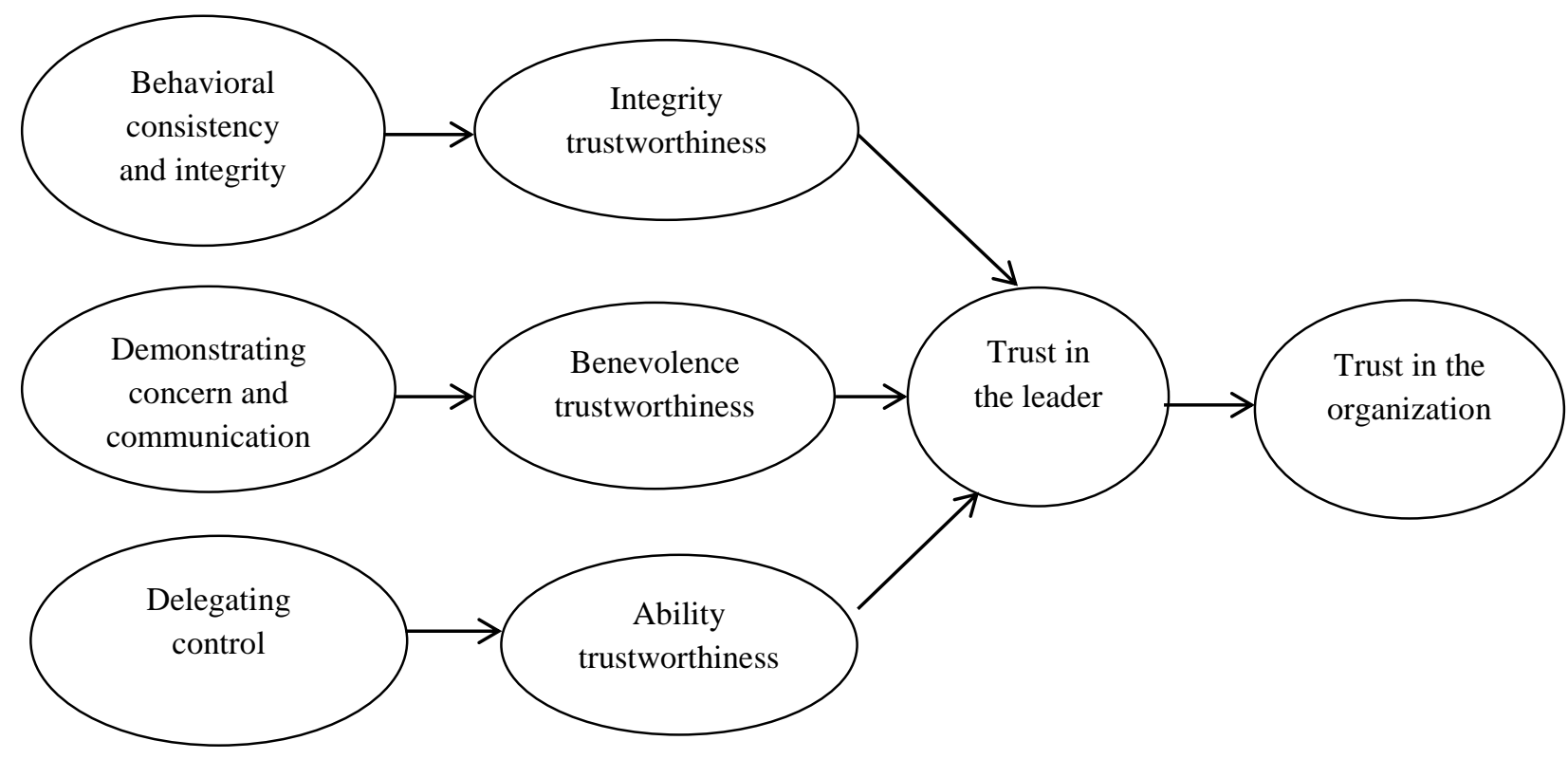

Figure 1. Conceptual model illustrating the three dimension models 


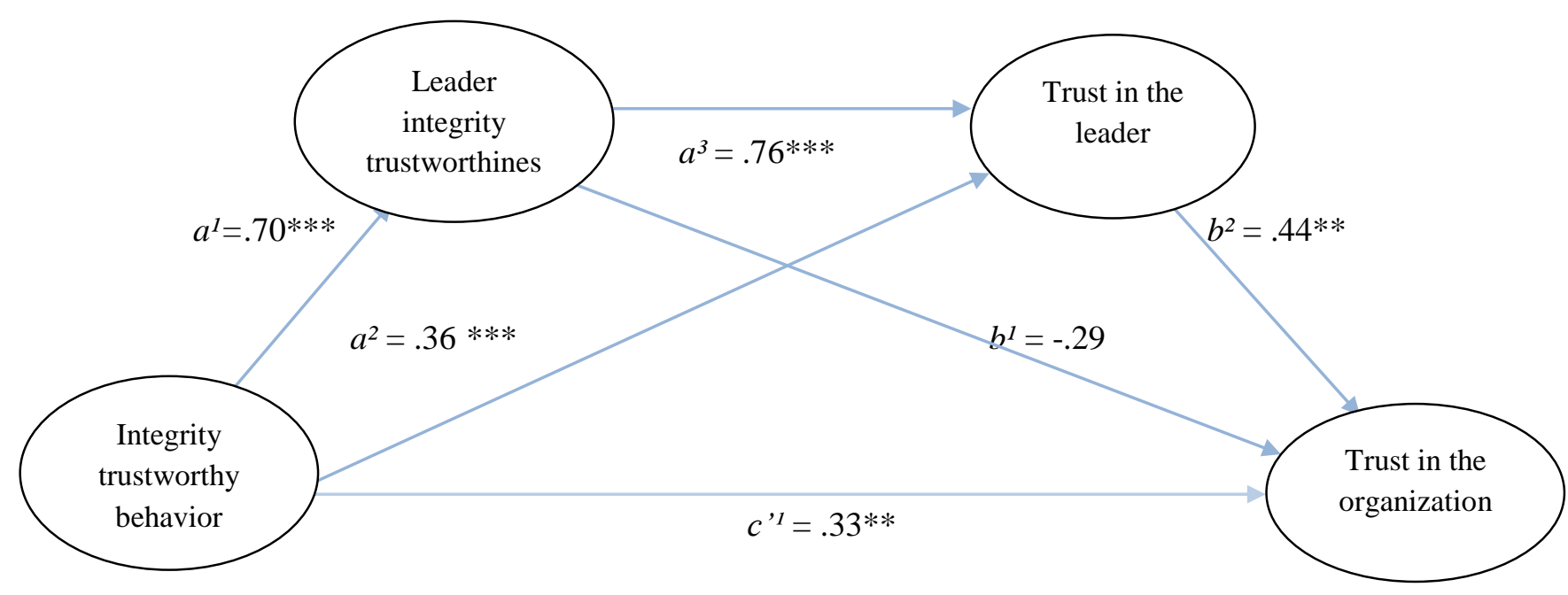

$*_{p}<.05 . * *_{p}<.01 . * * * p<.001$.

Figure 2: Model coefficients for each of the indirect effects and direct effect for the integrity model 


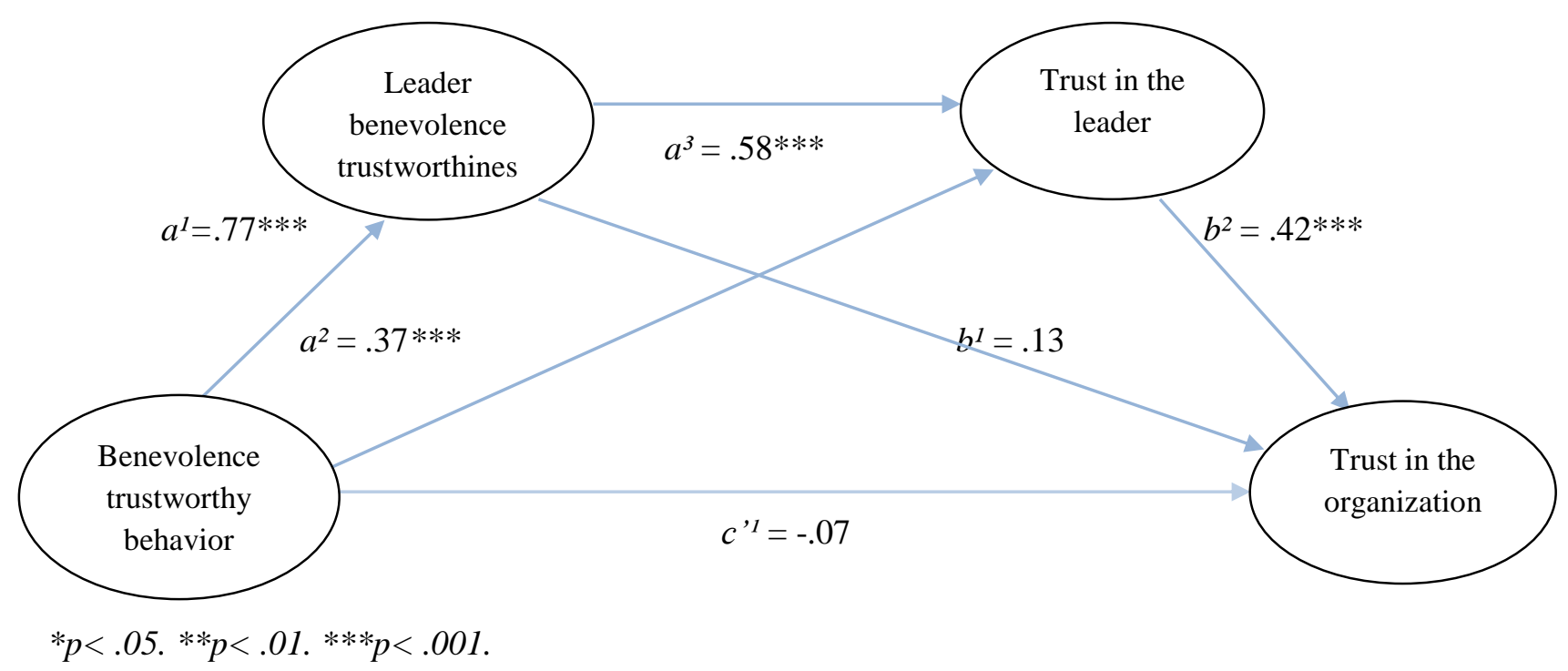

Figure 3: Model coefficients for each of the indirect effects and direct effect for the benevolence model 


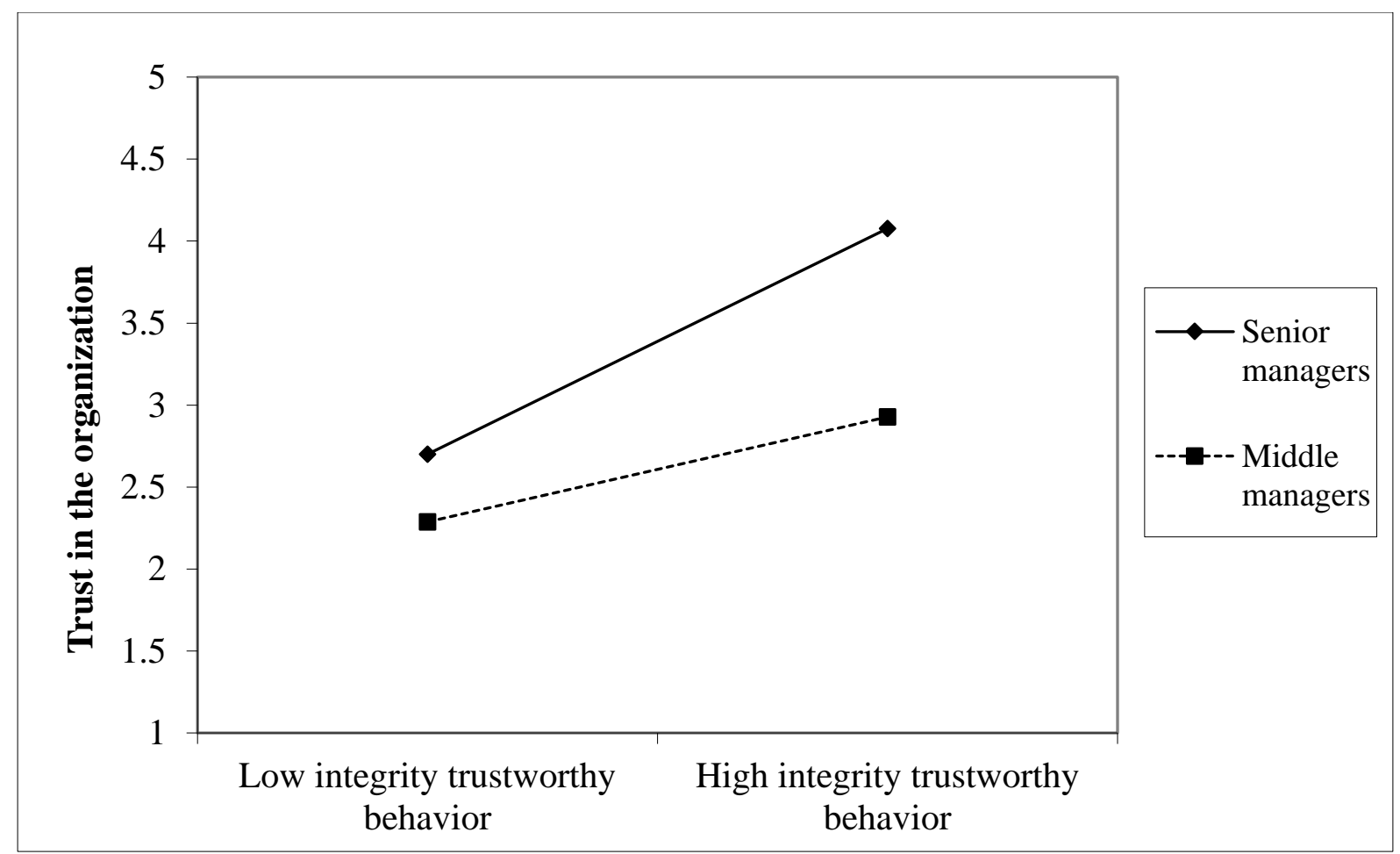

Figure 4. Perceptions of organizational trust as a function of integrity trustworthy behavior for senior and middle managers. 


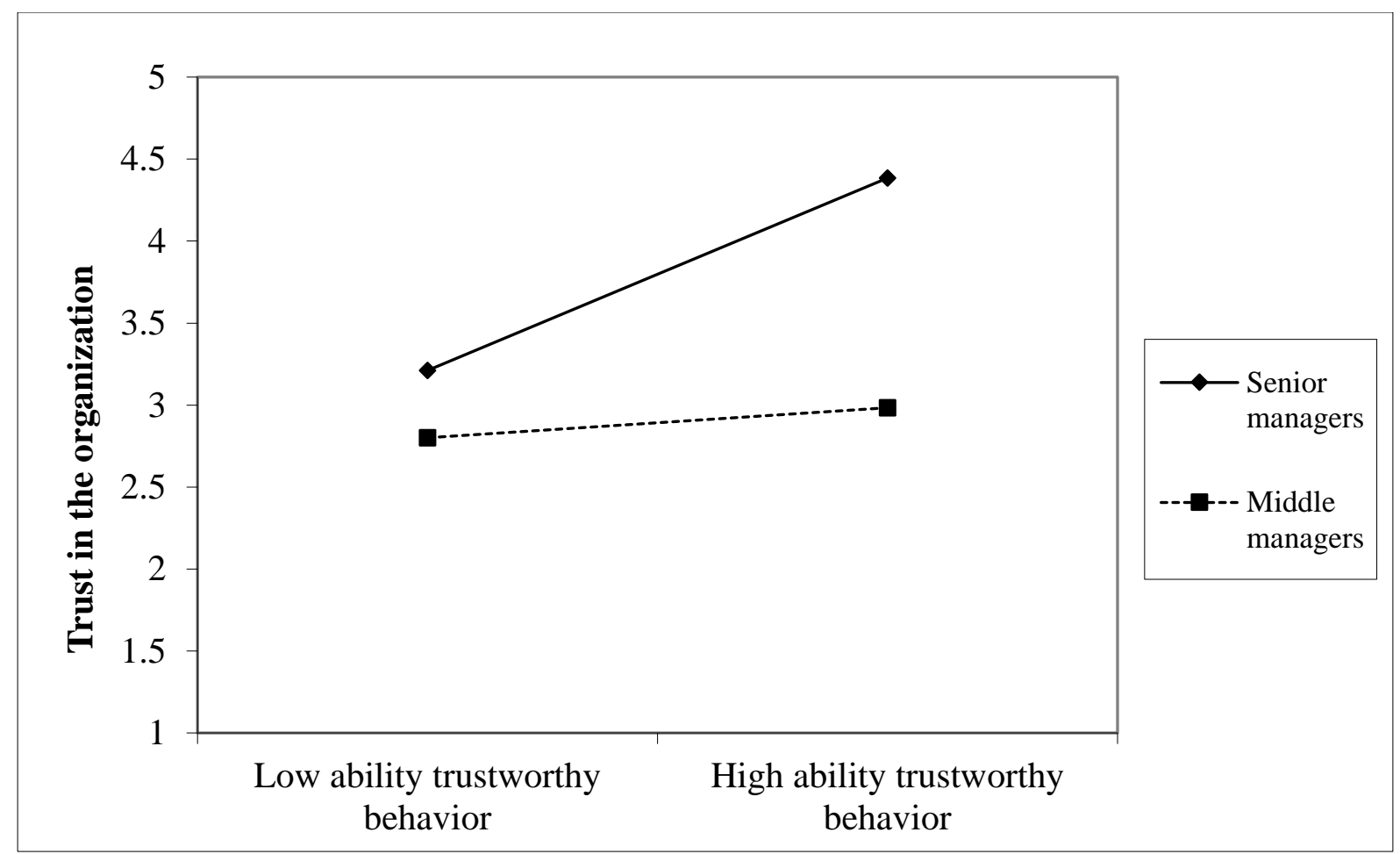

Figure 5. Perceptions of organizational trust as a function of ability trustworthy behavior for senior and middle managers. 